\title{
Parasite-Produced MIF Cytokine: Role in Immune Evasion, Invasion, and Pathogenesis
}

\author{
Swagata Ghosh ${ }^{1}$, Nona Jiang ${ }^{2}$, Laura Farr ${ }^{1}$, Renay Ngobeni ${ }^{3}$ and Shannon Moonah ${ }^{1 *}$ \\ ${ }^{1}$ Division of Infectious Diseases and International Health, Department of Medicine, University of Virginia, Charlottesville, VA, \\ United States, ${ }^{2}$ Department of Medicine, Yale University, New Haven, CT, United States, ${ }^{3}$ Department of Environmental, \\ Water, and Earth Sciences, Tshwane University of Technology, Pretoria, South Africa
}

OPEN ACCESS

Edited by:

Jude Ezeh Uzonna,

University of Manitoba, Canada

Reviewed by:

Nahed Ismail,

University of Illinois at Chicago,

United States

Theo Araújo-Santos,

Federal University of Western

Bahia, Brazi

Michael Makokha Opata,

University of Texas Medical Branch

at Galveston, United States

*Correspondence:

Shannon Moonah

sm5fe@virginia.edu

Specialty section:

This article was submitted to

Microbial Immunology,

a section of the journal

Frontiers in Immunology

Received: 27 May 2019 Accepted: 07 August 2019

Published: 21 August 2019

Citation:

Ghosh S, Jiang N, Farr L, Ngobeni R and Moonah S (2019)

Parasite-Produced MIF Cytokine: Role in Immune Evasion, Invasion, and

Pathogenesis.

Front. Immunol. 10:1995.

doi: 10.3389/fimmu.2019.01995
Protozoan parasites represent a major threat to health and contribute significantly to morbidity and mortality worldwide, especially in developing countries. This is further compounded by lack of effective vaccines, drug resistance and toxicity associated with current therapies. Multiple protozoans, including Plasmodium, Entamoeba, Toxoplasma, and Leishmania produce homologs of the cytokine MIF. These parasite MIF homologs are capable of altering the host immune response during infection, and play a role in immune evasion, invasion and pathogenesis. This minireview outlines well-established and emerging literature on the role of parasite MIF homologs in disease, and their potential as targets for therapeutic and preventive interventions.

Keywords: MIF, cytokine, protozoan parasites, host-parasite interaction, immune evasion, immunopathology, immunotherapeutic target

\section{INTRODUCTION}

Protozoan parasites cause more than one million deaths annually. For example, Plasmodium falciparum, a protozoan parasite responsible for most human malaria, accounted for an estimated 200 million malaria cases and roughly 500,000 malaria deaths in $2015(1,2)$. The protozoan parasite Leishmania causes an estimated 50,000 deaths per annum through visceral leishmaniasis (3). Entamoeba histolytica is a protozoan parasite that causes colitis (inflammatory diarrhea). Millions of people are infected with E. histolytica, making amebic colitis a leading cause of severe diarrhea, estimated to kill more than 50,000-100,000 people each year (4-6). The protozoan parasite Toxoplasma gondii, which affects up to a third of the world's population, is adapted to survive and abide chronically in its host (7). The threats posed by protozoan parasites are further compounded by lack of any effective parasite vaccine, emerging drug resistance, drug toxicity, poor efficacy, and limited antimicrobial options $(5,8,9)$. Therefore, identifying novel targets for therapeutic intervention and vaccine prevention is urgently needed. Pathogenic protozoans produce virulence factors that enable immune response evasion and host invasion which promote their transmission and ability to cause human disease (10). Targeting these virulence factors required to cause host damage and disease might successfully treat and prevent these infectious diseases.

The pathogenesis of protozoan diseases is highly variable, and is often influenced by individual life cycles and immunologic consequences of infection. The complicated life cycle of Plasmodium begins when an infected female anopheles mosquito injects sporozoites into the bloodstream of a human during a blood meal, which travel to the liver, before emerging to release merozoites into the bloodstream. These merozoites invade and multiply within erythrocytes to rupture, releasing more merozoites, and continually perpetuating invasion by the parasite. Plasmodium promotes 
its survival by avoiding excessive exposure to the immune system by infecting hepatocytes and erythrocytes. Clinical symptoms are associated with the rupture of infected erythrocytes and the release of malarial toxins, and include fever, severe hemolytic anemia and other systemic features. Merozoites also develop into sexual forms known as gametocytes, which are ingested during mosquito bites to continue the life cycle (11). Similarly, Leishmania is also a vector-borne protozoan parasite, that is transmitted when Leishmania promastigotes are inoculated into the subdermis of the skin by the bite of an infected female phlebotomine sand fly. Leishmania is rapidly phagocytized by neutrophils. Promastigotes within dead infected neutrophils are taken up by host macrophages, morphing into the amastigote form. Depending on the species, amastigotes replicate within the macrophage locally to form disfiguring skin ulcers (cutaneous leishmaniasis) or disseminate to the bone marrow, liver, and spleen (visceral leishmaniasis) which is fatal if untreated (12-15).

In contrast to these vector-borne infections, the transmission of the highly prevalent protozoa, Toxoplasma gondii, is fecal-oral, through the ingestion of the oocyst from material contaminated with feline feces or undercooked meat infected with tissue cysts. Following intestinal infection, tachyzoites form, and then disseminate to other tissues in the body including the brain, eye, muscle, liver, and placenta. Like Leishmania, Toxoplasma is able to infect phagocytes, which facilitates successful infection. Symptoms of primary infection include fever, adenopathy, headache, and myalgia. The stimulation of a robust immune response controls the acute infection, driving the parasite into a chronic, asymptomatic stage allowing Toxoplasma to survive as bradyzoites in cyst forms within multiple tissues capable of later reactivation (7). Infection with E. histolytica also begins with the ingestion of fecally contaminated food or water, but has a relatively simpler life cycle. E. histolytica exists as either infective cysts which are ingested or transforms into invasive trophozoites that penetrate the mucus layer of the large intestine to cause colitis leading to diarrhea, dysentery, and colonic ulceration. The trophozoites can also on occasion disseminate to cause extraintestinal disease, with a particular predilection for the liver leading to amebic liver abscess (16). Thus, in order to complete their life cycle, all of these protozoa must be able to invade and pass from host to host while avoiding clearance by the immune response. In this minireview, we describe how protozoa secrete a specific protein macrophage migration inhibitory factor to accomplish this task.

\section{MACROPHAGE MIGRATION INHIBITORY FACTOR}

Macrophage migration inhibitory factor (MIF) was one of the first cytokines to be discovered over 50 years ago $(17,18)$. Since then, a significant amount of information has been accumulated regarding the role of MIF in normal physiology and pathology. MIF is a well-studied pleiotropic inflammatory protein, expressed by a variety of cells, and is a critical upstream mediator of innate immunity. While MIF's exact molecular mechanism is not fully understood, partial pathways of MIF signaling have been established. For example, secreted MIF binds to its receptor, CD74, on immune cells, activates the ERK1/2 and PI3K/Akt pathways, and modulates expression of various cytokines, e.g., TNF- $\alpha$, IL-6, IL-8, and IL-12 (19). MIF may also bind to CXCR2 and CXCR4, which may be responsible for its chemotactic properties. In addition, MIF stimulates the production of matrix metalloproteinases (20). Therefore, it is not surprising that MIF plays an important role in immunity and that excess MIF expression has been linked to exaggerated inflammation and immunopathology in diseases such as rheumatoid arthritis, and inflammatory bowel disease $(19,21,22)$.

The proinflammatory properties of MIF also make it a crucial mediator in the immune response against a wide variety of pathogens including parasites (23). In protozoan infection, host MIF play a key role in reducing parasite burden through stimulation of both innate and adaptive immune cells. Mechanistically, host MIF can stimulate nitric oxide production by macrophages and dendritic cells, which in turn eliminates parasites such as Leishmania, Toxoplasma, and Trypanosoma $(13,23,24)$. MIF can also be harmful to the host. That is, MIF production has been linked to pathology during malaria and $T$. brucei infection, by promoting inflammationinduced tissue damage $(21,25,26)$. The role of host MIF during parasite infections has been well-reviewed elsewhere $(23,24,27)$.

Counterintuitively, many pathogenic protozoans, including Plasmodium, Entamoeba, Toxoplasma, and Leishmania, produce their own MIF cytokine. These secreted parasite-produced MIF are structurally similar to human MIF, bind the MIF receptor (CD74), and stimulate immune cells and epithelial cells to cause the release of cytokines such as TNF- $\alpha$, IL-8, and IL12 (28-35). While it seems counterintuitive for protozoans to secrete a proinflammatory cytokine, it appears they have an important role in the parasite life cycle. Here, we focus on MIF produced by medically important protozoans, highlighting the recent contributions that have improved our understanding of the role of protozoan MIF in immune evasion, invasion, and pathogenesis (Figure 1).

\section{IMMUNE EVASION}

The host deploys a robust immune response to prevent parasite invasion, clear the infectious pathogen, and prevent re-infection. However, parasites have developed a remarkable number of mechanisms to evade these attacks (10). For example, Leishmania has developed ways to modify host cell signaling pathways, in order to survive and persist in host cells. Leishmania targets macrophages, which, interestingly, are the primary immune cells involved in the parasite's eradication (13). Leishmania major encodes two isoforms of MIF which facilitates its persistence in macrophages and contributes to its evasion from immune clearance. L. major MIF binds to CD74 on infected macrophages, activating the ERK1/2 pathway and preventing apoptosis of macrophages $(35,36)$. Infected macrophages then survive a sufficiently long enough time for the parasite to avoid excessive 


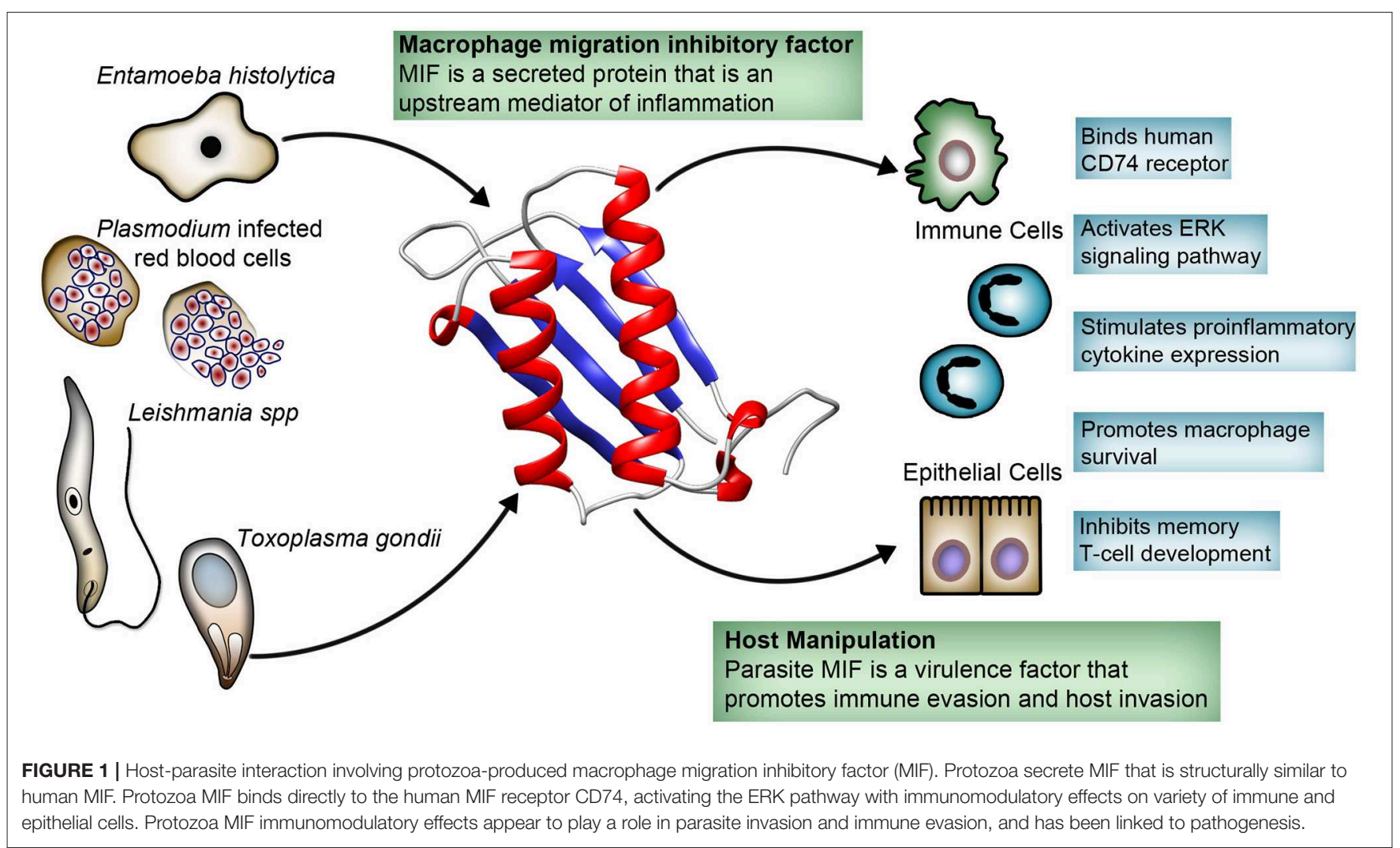

exposure to the immune system and complete its infectious life cycle.

The lack of protective immunity against re-infection is one of the biggest problems in controlling the transmission of protozoan infections. An adequate amount of protective memory T-cells are needed to fight off re-infection (37). Recent research in parasite MIF has provided a mechanism by which parasites evade the immune response by interfering with the development of immunological memory during infection, allowing them to re-infect their host $(28,29,35)$. Using mouse models, researchers found that the proinflammatory effects of both Plasmodium and Leishmania MIF can manipulate T-cell differentiation. Plasmodium MIF enhances the production of IFN- $\gamma$ and IL-12 which reduces the anti-Plasmodium bloodstage CD4 T-cell response. Mice infected with MIF-deficient $P$. berghei had reduced levels of these cytokines. This reduced inflammatory state correlated with improved survival of CD4 T helper cells. As a result, mice were able to develop effective T-cell memory when infected with MIF-deficient parasites which provided a protective response against a subsequent $P$. berghei infection. Leishmania MIF cause T-cells to develop into exhausted $\mathrm{PD}-1^{+}$short-lived effector cells with reduced IL-7R expression, which is needed to produce and maintain memory cells $(28,29,35)$. These short-lived cells die during infection, and the long-lived memory $\mathrm{T}$-cells required to prevent re-infection were not produced in adequate amounts (29). This MIF-induced lack of memory cells resulted in parasitic re-infection.
Recent clinical observations also support these findings. It was observed that in a cohort of children in an area endemic for amebiasis, those who lacked adequate amounts of antibodies against E. histolytica MIF were not protected from future infection (Figure 2A). The authors postulated that $E$. histolytica MIF might share similar properties to Plasmodium and Leishmania MIF. That is, E. histolytica MIF might also inhibit the development of sufficient amounts of memory cells. Thus, antibodies against E. histolytica MIF would block this effect resulting in adequate amounts of memory cells to protect against reinfection (32). Nevertheless, further studies are needed to confirm this theory. Also, the role of Toxoplasma MIF in immune evasion remains largely understudied.

\section{INVASION}

Host tissue invasion by extracellular or intracellular protozoan parasites play an important role in the pathogenesis of disease. The extent of tissue invasion by extracellular parasites correlates with the degree of disease severity (16). For example, the depth of tissue invasion is associated with worse outcomes in clinicopathological studies of patients with severe amebic colitis $(38,39)$. On the other hand, obligate intracellular parasites invade host cells to complete their life cycle $(13,40)$. Several parasite factors are known to contribute to the invasion process. Recent studies have implicated parasite MIF proteins in facilitating invasion and dissemination of several protozoan parasites. 


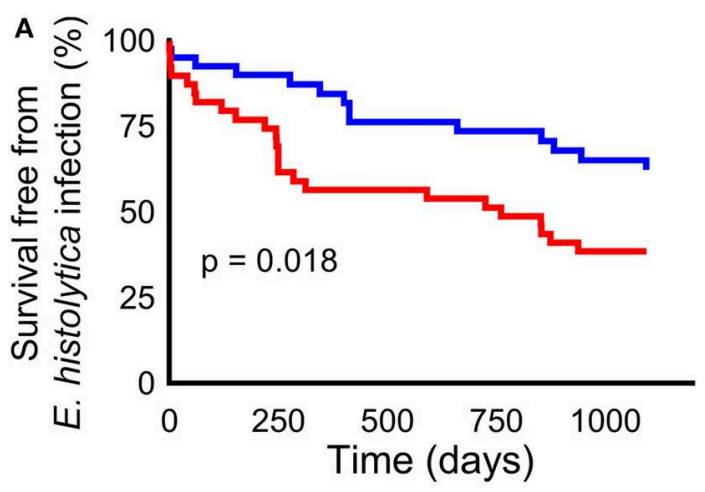

B

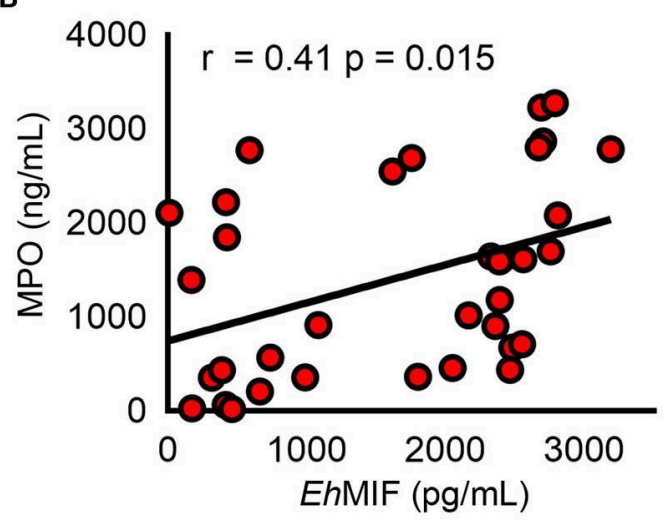

FIGURE 2 | E. histolyica MIF (EhMIF) in human amebiasis. (A) Children in the top 50th percentile for anti- EhMIF antibody (blue line) had a significantly higher probability of survival free of $E$. histolytica infection than children within lower 50th percentile (red line). (B) Significant positive correlation between fecal EhMIF levels and the myeloperoxidase (MPO) marker of intestinal inflammation in persons with amebiasis $(n=35)$. Panels are reproduced from (17) with permission.

The extracellular matrix (ECM) is a network of proteins that provides tissue support and represents a major physical barrier to the parasite invasion. Matrix metalloproteinases (MMPs) are enzymes primarily responsible for ECM breakdown (41). Protozoa infections trigger an inflammatory response which leads to MMP overexpression, resulting in ECM breakdown. ECM degradation facilitates cell movement, and allows immune cell infiltration at the site of infection for host defense (42). Parasites have developed mechanisms to exploit the activities of MMPs to promote their invasion. For example, MMPs play a critical role in E. histolytica invasion. MMP expression is increased in human amebic colitis and inhibition of MMP prevented E. histolytica invasion in a human colonic explant model $(32,43,44)$. Recently, a causal relationship between $E$. histolytica-produced MIF and gut inflammation was established using cellular and mouse models of amebic colitis. In the same study, researchers found that E. histolytica MIF-induced inflammation resulted in increased MMP production (32). Therefore, E. histolytica parasites appear to produce MIF as a virulence factor to exploit the inflammatory response to promote tissue invasion.
As mentioned above, neutrophils are the first immune cells to reach the site of Leishmania infection after a sand fly bite, and their uptake by neutrophils followed by macrophage engulfment contributes to leishmanial parasites infectivity and assist in life cycle progression (12-14). Neutrophils are shortlived phagocytes that act as a "Trojan horse" used by Leishmania parasites to obtain entry into macrophages thereby avoiding cell activation (15). Whether there are leishmanial factors that drive this neutrophil infiltration remains largely unanswered. While host MIF exhibits chemokine-like activities through interactions with the chemokine receptors CXCR2 and CXCR4 $(45,46)$, protozoan MIF-CXCR2 and CXCR4 interactions remain unclear.

Similar to Leishmania, T. gondii induces immune cell infiltration and not only evades their killing, but also hitches a ride in these cells to spread infection $(47,48)$. T. gondii must cross the intestinal barrier for it to advance from the gut to sites of secondary infection, and tachyzoites are often found in neutrophils in the gut lumen. In vitro studies have indicated that $T$. gondii MIF stimulates the production of the potent chemoattractant IL-8 from human cells. In an attempt to explain why this would benefit the parasite, it has been suggested that MIF-induced IL-8 production leads to neutrophil recruitment. Infected neutrophils, which are incapable of clearing the parasite, serve as motile reservoirs for $T$. gondii infection, facilitating the transepithelial migration of the parasite $(30,48,49)$. While plausible, additional studies are warranted to validate the role of Toxoplasma MIF in invasion.

\section{PATHOGENESIS}

During protozoan infections, an unbalanced inflammatory reaction increases tissue destruction which leads to clinical disease. The inflammatory response is essential in that it provides protection against invading microbes. However, protozoan parasites have developed effective strategies to evade the immune response, avoid elimination, and persist in their host, which exacerbates the damage caused by the lingering inflammatory response to invading parasites (10). This is further compounded by the fact that these parasites secrete MIF cytokine that can directly drive inflammation.

Host cytokines released during Plasmodium infection contribute to severe malaria. For example, high TNF- $\alpha$ production is a strong predictor of severe malarial anemia and cerebral malaria in children $(50,51)$. $P$. falciparum MIF was shown to stimulate TNF- $\alpha$ secretion by immune cells in-vitro. Also, circulating serum $P$. falciparum MIF levels positively correlated with serum TNF- $\alpha$ levels in malaria patients, and higher P. falciparum MIF levels were observed in patients with severe malarial anemia and cerebral malaria $(25,28)$. These findings suggest that $P$. falciparum MIF is likely contributing to immunopathogenesis during malaria.

Neutrophil infiltration is a hallmark of amebic colitis. Neutrophils generate oxygen free radicals that are capable of killing the E. histolyica parasite. That said, E. histolytica has developed several strategies to counter and survive neutrophil killing (52-54). This results in an excessive and persistent 
neutrophil response in the gut that has been shown to be associated with the most severe forms of human amebiasis, which also carry high fatality $(6,55-57)$. E. histolyica MIF plays an essential role in neutrophil infiltration during infection. E. histolytica MIF was shown to stimulate IL-8 and the murine IL8 homolog KC (potent neutrophil chemoattractants), resulting in neutrophil infiltration and tissue destruction in cellular and mouse models. A recent human study found that gut E. histolyica MIF levels correlated with intestinal inflammation severity [Figure 2B; $(32,33)$ ].

Macrophages also play a crucial role in protozoan MIFinduced immunopathology. In vitro studies show that $E$. histolyica MIF directly enhances TNF- $\alpha$ and IL- 6 production from macrophages (31). Both cytokines cause collateral tissue injury in amebic colitis and liver abscess (10, 58). In a mouse model of Leishmania infection, Leishmania MIF upregulated inflammatory and innate immune signaling in infected macrophages, such as CXCL1, TLR2, and TNF- $\alpha$, when compared to $M I F^{-/-}$strains (35). Taken together, this proinflammatory phenotype, extending the survival of infected macrophages, and defective adaptive immune response supports the contribution of Leishmania MIF to the chronic destructive inflammatory state observed in leishmaniasis.

\section{OTHER PROTOZOANS PRODUCING MIF}

Other medically important protozoans include Trichomonas, Giardia, Trypanosoma, Acanthamoeba, and Naegleria. MIF orthologs have been discovered in Trichomonas and Giardia. The structure of Giardia MIF has been solved with a characterization similar to human MIF, but its role in infection is not wellunderstood (59). Surprisingly, MIF orthologs have not been characterized in Trypanosoma, Acanthamoeba, and Naegleria. However, incomplete genome assembly and annotation may limit in-silico analysis and explain why MIF has yet to be identified in these protozoans.

Inflammation is a critical component of tumor progression and many cancers, including prostate cancer, arise from sites

\section{REFERENCES}

1. World Health Organization. World Malaria Report 2015. (2016). Geneva: World Health Organization.

2. Gardner MJ, Hall N, Fung E, White O, Berriman M, Hyman RW, et al. Genome sequence of the human malaria parasite Plasmodium falciparum. Nature. (2002) 419:498-511.

3. World Health Organization. Control of the leishmaniases. World Health Organ Tech Rep Ser. (2010) xii-xiii, 1-186.

4. Lozano R, Naghavi M, Foreman K, Lim S, Shibuya K, Aboyans V, et al. Global and regional mortality from 235 causes of death for 20 age groups in 1990 and 2010: a systematic analysis for the Global Burden of Disease Study 2010. Lancet. (2012) 380:2095-128.

5. Shirley DT, Farr L, Watanabe K, Moonah S. A review of the global burden, new diagnostics, and current therapeutics for Amebiasis. Open Forum Infect Dis. (2018) 5:ofy161. doi: 10.1093/ofid/ofy161

6. Shirley DA, Moonah S. Fulminant amebic colitis after corticosteroid therapy: a systematic review. PLoS Negl Trop Dis. (2016) 10:e0004879. doi: 10.1371/journal.pntd.0004879 of infection and chronic inflammation (60,61). Trichomonas vaginalis is a sexually transmitted parasite that can colonize the prostate in men. T. vaginalis also secretes MIF which has pro-inflammatory properties. In addition to stimulating the production of IL- 8 and IL- 6 cytokines, Trichomonas MIF binds to the human CD74 MIF receptor triggering the activation of the pro-proliferative ERK and P13K/Akt pathways in prostate epithelial cells. Trichomonas MIF-driven inflammation and cell proliferation, was linked to the promotion and progression of prostate cancer (62).

\section{CONCLUSION}

Recent studies have made it increasingly clear that parasiteproduced MIF is a virulence factor that play a significant role in host-parasite interactions and contributes to pathogenesis. Despite these advances, key questions remain unanswered. Such as, can we translate these findings to provide beneficial interventions to patients infected with these pathogens? Do we know enough to intervene in a meaningful way? Protozoan MIF (P-MIF) appears to be a logical candidate for further evaluation as an effective immunotherapeutic target given the accumulation of data showing that: (i) infected persons naturally make antibodies against P-MIF, (ii) anti-P-MIF do not cross-react with host MIF, and (iii) neutralizing antibodies inhibit P-MIF activity and therefore prevent re-infection and reduce immunopathology.

\section{AUTHOR CONTRIBUTIONS}

SG, NJ, LF, RN, and SM wrote different sections, edited, and reviewed the manuscript.

\section{FUNDING}

This work was supported by National Institutes of Health (NIH) R01AI026649-27S1, K08AI119181, UVA seed grant, and the Robert Wood Johnson Foundation-Harold Amos Medical Faculty Development Program Award.

7. Randall LM, Hunter CA. Parasite dissemination and the pathogenesis of toxoplasmosis. Eur J Microbiol Immunol. (2011) 1:3-9. doi: 10.1556/EuJMI. 1.2011.1.3

8. Debnath A, Parsonage D, Andrade RM, He C, Cobo ER, Hirata K, et al. A high-throughput drug screen for Entamoeba histolytica identifies a new lead and target. Nat Med. (2012) 18:956-60. doi: 10.1038/nm.2758

9. Chong CR, Sullivan DJ. New uses for old drugs. Nature. (2007) 448:645. doi: $10.1038 / 448645$ a

10. Moonah SN, Jiang NM, Petri WA. Host immune response to intestinal amebiasis. PLoS Pathog. (2013) 9:e1003489. doi: 10.1371/journal.ppat.1003489

11. Mawson AR. The pathogenesis of malaria: a new perspective. Pathog Glob Health. (2013) 107:122-9. doi: 10.1179/2047773213Y.0000 000084

12. Kaye P, Scott P. Leishmaniasis: complexity at the host-pathogen interface. Nat Rev Microbiol. (2011) 9:604-15. doi: 10.1038/nrmicro2608

13. Gupta G, Oghumu S, Satoskar AR. Mechanisms of immune evasion in leishmaniasis. In: Sariaslani S, Gadd GM, editors. Advances in Applied Microbiology. San Diego, CA: Elsevier (2013). p. 155-84. doi: 10.1016/B978-0-12-407679-2.00005-3 
14. Peters NC, Egen JG, Secundino N, Debrabant A, Kimblin N, Kamhawi $\mathrm{S}$, et al. In vivo imaging reveals an essential role for neutrophils in leishmaniasis transmitted by sand flies. Science. (2008) 321:970-74. doi: $10.1126 /$ science. 1159194

15. Liu D, Uzonna JE. The early interaction of Leishmania with macrophages and dendritic cells and its influence on the host immune response. Front Cell Infec Microbiol. (2012) 2:83. doi: 10.3389/fcimb.2012.00083

16. Ghosh S, Padalia J, Moonah S. Tissue destruction caused by entamoeba histolytica parasite: cell death, inflammation, invasion, and the gut microbiome. Curr Clin Microbiol Rep. (2019) 6:51-7. doi: 10.1007/s40588-019-0113-6

17. Bloom BR, Bennett B. Mechanism of a reaction in vitro associated with delayed-type hypersensitivity. Science. (1966) 153:80-2. doi: $10.1126 /$ science. 153.3731 .80

18. David JR. Delayed hypersensitivity in vitro: its mediation by cell-free substances formed by lymphoid cell-antigen interaction. Proc Natl Acad Sci USA. (1966) 56:72-77. doi: 10.1073/pnas.56.1.72

19. Harris J, VanPatten S, Deen NS, Al-Abed Y, Morand EF. Rediscovering MIF: New Tricks for an Old Cytokine. Trends in immunology, 2019. doi: 10.1016/j.it.2019.03.002

20. Bai F, Asojo OA, Cirillo P, Ciustea M, Ledizet M, Aristoff PA, et al. A novel allosteric inhibitor of macrophage migration inhibitory factor (MIF). J Biol Chem. (2012) 287:30653-63. doi: 10.1074/jbc.M112.385583

21. Calandra T, Roger T. Macrophage migration inhibitory factor: a regulator of innate immunity. Nat Rev Immunol. (2003) 3:791. doi: 10.1038/nri1200

22. de Jong YP, Abadia-Molina AC, Satoskar AR, Clarke K, Rietdijk ST, Faubion WA, et al. Development of chronic colitis is dependent on the cytokine MI. Nat Immunol. (2001) 2:1061-6. doi: 10.1038/ni720

23. Terrazas C, Stock JC, Kimble J, Moretti E, Varikuti S, Satoskar AR. The role of MIF in parasitic infections. In: Bucala R, Bernhagen J, editors. MIF Family Cytokines in Innate Immunity and Homeostasis. Cham: Springer International Publishing (2017). p. 203-19. doi: 10.1007/978-3-319-52354-5_13

24. Bozza MT, Martins YC, Carneiro LA, Paiva CN. Macrophage migration inhibitory factor in protozoan infections. J Parasitol Res. (2012) 2012:413052. doi: 10.1155/2012/413052

25. Han C, Lin Y, Shan G, Zhang Z, Sun X, Wang Z, et al. Plasma concentration of malaria parasite-derived macrophage migration inhibitory factor in uncomplicated malaria patients correlates with parasitemia and disease severity. Clin Vaccine Immunol. (2010) 17:1524-32. doi: 10.1128/CVI.00149-10

26. Stijlemans B, Leng L, Brys L, Sparkes A, Vansintjan L, Caljon G, et al.Stijlemans B, et al. MIF contributes to Trypanosoma brucei associated immunopathogenicity development. PLoS pathogens. (2014) 10:e1004414. doi: 10.1371/journal.ppat.1004414

27. Rosado Jde D, Rodriguez-Sosa M. Macrophage migration inhibitory factor (MIF): a key player in protozoan infections. Int J Biol Sci. (2011) 7:1239-56. doi: 10.7150/ijbs.7.1239

28. Sun T, Holowka T, Song Y, Zierow S, Leng L, Chen Y, et al. A Plasmodiumencoded cytokine suppresses T-cell immunity during malaria. Proc Natl Acad Sci USA. (2012) 109:E2117-26. doi: 10.1073/pnas.1206573109

29. Baeza Garcia A, Siu E, Sun T, Exler V, Brito L, Hekele A, et al. Neutralization of the Plasmodium-encoded MIF ortholog confers protective immunity against malaria infection. Nat Commun. (2018) 9:2714. doi: 10.1038/s41467-018-05041-7

30. Sommerville C, Richardson JM, Williams RA, Mottram JC, Roberts CW, Alexander J, et al. Biochemical and immunological characterization of Toxoplasma gondii macrophage migration inhibitory factor. J Biol Chem. (2013) 288:12733-41. doi: 10.1074/jbc.M112.419911

31. Moonah SN, Abhyankar MM, Haque R, Petri WA. The macrophage migration inhibitory factor homolog of Entamoeba histolytica binds to and immunomodulates host macrophages. Infect Immun. (2014) 82:3523-30. doi: 10.1128/IAI.01812-14

32. Ngobeni R, Abhyankar MM, Jiang NM, Farr LA, Samie A, Haque R, et al. Entamoeba histolytica-encoded homolog of macrophage migration inhibitory factor contributes to mucosal inflammation during amebic colitis. J Infect Dis. (2017) 215:1294-302. doi: 10.1093/infdis/jix076

33. Ghosh S, Leaton LA, Farr L, Barfield A, Moonah S. Interaction between parasite-encoded JAB1/CSN5 and macrophage migration inhibitory factor proteins attenuates its proinflammatory function. Sci Rep. (2018) 8:10241 doi: 10.1038/s41598-018-28625-1

34. Twu O, de Miguel N, Lustig G, Stevens GC, Vashisht AA, Wohlschlegel JA, et al. Trichomonas vaginalis exosomes deliver cargo to host cells and mediate host:parasite interactions. PLOS Pathog. (2013) 9:e1003482. doi: 10.1371/journal.ppat.1003482

35. Holowka T, Castilho TM, Garcia AB, Sun T, McMahon-Pratt D, Bucala R. Leishmania-encoded orthologs of macrophage migration inhibitory factor regulate host immunity to promote parasite persistence. FASEB J. (2016) 30:2249-2265. doi: 10.1096/fj.201500189R

36. Kamir D, Zierow S, Leng L, Cho Y, Diaz Y, Griffith J, et al. A Leishmania ortholog of macrophage migration inhibitory factor modulates host macrophage responses. J Immunol. (2008) 180:8250-61. doi: 10.4049/jimmunol.180.12.8250

37. Riley EM, Stewart VA. Immune mechanisms in malaria: new insights in vaccine development. Nat Med. (2013) 19:168. doi: 10.1038/nm.3083

38. Chaturvedi R, Gupte PA, Joshi AS. Fulminant amoebic colitis: a clinicopathological study of 30 cases. Postgrad Med J. (2015) 91:200-5. doi: 10.1136/postgradmedj-2014-132597

39. Takahashi T, Gamboa-Dominguez A, Gomez-Mendez TJ, Remes JM, Rembis V, Martinez-Gonzalez D, et al. Fulminant amebic colitis: analysis of 55 cases. Dis Colon Rectum. (1997) 40:1362-7. doi: 10.1007/BF02050824

40. Sibley LD. Invasion and intracellular survival by protozoan parasites. Immunol Rev. (2011) 240:72-91. doi: 10.1111/j.1600-065X.2010.00990.x

41. Bonnans C, Chou J, Werb Z. Remodelling the extracellular matrix in development and disease. Nat Rev Mol Cell Biol. (2014) 15:786-801. doi: $10.1038 / \mathrm{nrm} 3904$

42. Geurts N, Opdenakker G, Van den Steen PE. Matrix metalloproteinases as therapeutic targets in protozoan parasitic infections. Pharmacol Ther. (2012) 133:257-79. doi: 10.1016/j.pharmthera.2011.11.008

43. Thibeaux R, Avé P, Bernier M, Morcelet M, Frileux P, Guillén N, et al. The parasite Entamoeba histolytica exploits the activities of human matrix metalloproteinases to invade colonic tissue. Nat Commun. (2014) 5:5142. doi: $10.1038 /$ ncomms6142

44. Peterson KM, Guo X, Elkahloun AG, Mondal D, Bardhan PK, Sugawara A, et al. expression of REG $1 \mathrm{~A}$ and REG $1 \mathrm{~B}$ is increased during acute amebic colitis. Parasitol Int. (2011) 60:296-300. doi: 10.1016/j.parint.2011.04.005

45. Bernhagen J, Krohn R, Lue H, Gregory JL, Zernecke A, Koenen RR, et al. MIF is a noncognate ligand of CXC chemokine receptors in inflammatory and atherogenic cell recruitment. Nat Med. (2007) 13:587. doi: 10.1038/ nm1567

46. Weber C, Kraemer S, Drechsler M, Lue H, Koenen RR, Kapurniotu A, et al. Structural determinants of MIF functions in CXCR2-mediated inflammatory and atherogenic leukocyte recruitment. Proc Natl Acad Sci USA. (2008) 105:16278-83. doi: 10.1073/pnas.0804017105

47. McCracken JM, Allen LA. Regulation of human neutrophil apoptosis and lifespan in health and disease. J Cell Death. (2014) 7:15-23. doi: 10.4137/JCD.S11038

48. Harker KS, Ueno N, Lodoen MB. Toxoplasma gondii dissemination: a parasite's journey through the infected host. Parasite Immunol. (2015) 37:1419. doi: 10.1111/pim.12163

49. Coombes JL, Charsar BA, Han SJ, Halkias J, Chan SW, Koshy AA, et al. Motile invaded neutrophils in the small intestine of Toxoplasma gondii-infected mice reveal a potential mechanism for parasite spread. Proc Natl Acad Sci USA. (2013) 110:E1913-22. doi: 10.1073/pnas.1220272110

50. Thuma PE, van Dijk J, Bucala R, Debebe Z, Nekhai S, Kuddo T, et al Distinct clinical and immunologic profiles in severe malarial anemia and cerebral malaria in Zambia. J Infect Dis. (2011) 203:211-9. doi: 10.1093/infdis/ jiq041

51. Perkins DJ, Were T, Davenport GC, Kempaiah P, Hittner JB, Ong'echa JM. Severe malarial anemia: innate immunity and pathogenesis. Int J Biol Sci. (2011) 7:1427-42. doi: 10.7150/ijbs.7.1427

52. Pineda E, Perdomo D. Entamoeba histolytica under oxidative stress: what countermeasure mechanisms are in place? Cells. (2017) 6:44. doi: 10.3390/cells6040044

53. Jeelani G, Nozaki T. Entamoeba thiol-based redox metabolism: a potential target for drug development. Molecul Biochem Parasitol. (2016) 206:39-45. doi: 10.1016/j.molbiopara.2016.01.004 
54. Andrade RM, Reed SL. New drug target in protozoan parasites: the role of thioredoxin reductase. Front Microbiol. (2015) 6:975. doi: $10.3389 /$ fmicb. 2015.00975

55. Sierra-Puente RE, Campos-Rodríguez R, Jarillo-Luna RA, MuñozFernández L, Rodríguez MG, Muñoz-Ortega $\mathrm{MH}$, et al. Expression of immune modulator cytokines in human fulminant amoebic colitis. Parasite Immunol. (2009) 31:384-91. doi: 10.1111/j.1365-3024.2009. 1118.x

56. Ventura-Juárez J, Barba-Gallardo LF, Muñoz-Fernández L, Martínez-Medina L, Márquez-Díaz F, Sosa-Díaz SJ, et al. Immunohistochemical characterization of human fulminant amoebic colitis. Parasite Immunol. (2007) 29:201-9. doi: 10.1111/j.1365-3024.2007.00934.x

57. Dickson-Gonzalez SM, de Uribe ML, Rodriguez-Morales AJ. Polymorphonuclear neutrophil infiltration intensity as consequence of Entamoeba histolytica density in amebic colitis. Surg Infect. (2009) 10:91-7. doi: 10.1089/sur.2008.011

58. Helk E, Bernin $H$, Ernst $T$, Ittrich $H$, Jacobs $T$, Heeren $J$, et al. TNFalpha-mediated liver destruction by Kupffer cells and Ly6Chi monocytes during Entamoeba histolytica infection. PLoS Pathog. (2013) 9:e1003096. doi: 10.1371/journal.ppat.1003096

59. Buchko GW, Abendroth J, Robinson H, Zhang Y, Hewitt SN, Edwards TE, et al. Crystal structure of a macrophage migration inhibitory factor from Giardia lamblia. J Struct Funct Genom. (2013) 14:47-57. doi: 10.1007/s10969-013-9155-9

60. Coussens LM, Werb Z. Inflammation and cancer. Nature. (2002) 420:860-7. doi: 10.1038/nature01322

61. Lippitz BE. Cytokine patterns in patients with cancer: a systematic review. Lancet Oncol. (2013) 14:e218-28. doi: 10.1016/S1470-2045(12)70582-X

62. Twu O, Dessí D, Vu A, Mercer F, Stevens GC, de Miguel N, et al. Trichomonas vaginalis homolog of macrophage migration inhibitory factor induces prostate cell growth, invasiveness, and inflammatory responses. Proc Natl Acad Sci USA. (2014) 111:8179-84. doi: 10.1073/pnas.1321884111

Conflict of Interest Statement: The authors declare that the research was conducted in the absence of any commercial or financial relationships that could be construed as a potential conflict of interest.

Copyright (C) 2019 Ghosh, Jiang, Farr, Ngobeni and Moonah. This is an open-access article distributed under the terms of the Creative Commons Attribution License (CC $B Y)$. The use, distribution or reproduction in other forums is permitted, provided the original author(s) and the copyright owner(s) are credited and that the original publication in this journal is cited, in accordance with accepted academic practice. No use, distribution or reproduction is permitted which does not comply with these terms. 